\title{
MATERNAL OUTCOME IN PRIMARY CAESAREAN SECTION AND SECONDARY CAESAREAN SECTION- A PROSPECTIVE OBSERVATIONAL STUDY
}

\author{
Lissiamma George1, Riya Susan Rajan²
}

${ }_{1}^{1}$ Additional Professor, Department of Obstetrics and Gynaecology, GMC, Thrissur, Kerala, India.

${ }^{2}$ Senior Resident, Department of Obstetrics and Gynaecology, GMC, Thrissur, Kerala, India.

\begin{tabular}{l}
\hline ABSTRACT \\
BACKGROUND \\
Caesarean section (CS) is a surgical intervention for the delivery of foetus. The rapid increase of CS rate throughout the world has \\
become a serious public health concern. Caesarean section has higher maternal surgical risks for current and subsequent \\
pregnancies. There are numerous factors which contribute to decrease in vaginal birth after caesarean section and although repeat \\
caesarean sections are associated with serious morbidity there are only a few studies which assess the risk of placenta praevia and \\
accreta in repeat caesarean section. Thus, this study was undertaken to find out the maternal outcome in those undergoing \\
primary and secondary CS in our population and to find out the common indications of primary caesarean section
\end{tabular}

\section{MATERIALS AND METHODS}

This is a prospective observational study done in the Department of Obstetrics and Gynaecology, Government Medical College, Thrissur, during the study period from 01.01.2016 to 31.12.2016 in women undergoing primary caesarean section and secondary caesarean section. The data was analysed with SPSS version 17.0 using chi square test taking $\mathrm{p}$ value of $<0.05$ as statistically significant.

\section{RESULTS}

Our study included 400 subjects, 200 patients each from those who had undergone primary and secondary caesarean section. Most common indications in primary CS group were fetal distress (20\%), failed induction (13\%), primi, breech (12\%) and in secondary CS group were previous CS with unfavourable cervix (63.5\%). Adhesions (60.5\%) and scar dehiscence (4\%) were most common intra op complications in secondary CS group and were statistically significant. PPH (19.8\%) was the most common intra operative complication in primary CS group.

\section{CONCLUSION}

In a developing country like India, where the population growth rate is ever increasing, women who have undergone a primary caesarean section must be counselled regarding the complications and possible maternal morbidity in subsequent pregnancies and must be motivated for trial of scar in subsequent pregnancies if there is no contraindication.

\section{KEY WORDS}

Primary Caesarean Section, Secondary Caesarean Section, Maternal Outcome.

HOW TO CITE THIS ARTICLE: George L, Rajan RS. Maternal outcome in primary caesarean section and secondary caesarean section- a prospective observational study. J. Evolution Med. Dent. Sci. 2019;8(09):590-593, DOI: 10.14260/jemds/2019/131

\section{BACKGROUND}

Caesarean delivery defines the birth of a foetus via laparotomy and then hysterotomy. There are two general types of caesarean delivery - primary refers to a first time hysterotomy and secondary denotes a uterus with one or more prior hysterotomy incisions. It was considered that CS rate of more than $15 \%$ indicates over utilization of the procedure (WHO 1985, 1993). The rapid increase of CS rate throughout the world has become a serious public health concern. More than $85 \%$ of these operations are for four reasons - prior caesarean delivery, fetal jeopardy, dystocia, or abnormal fetal presentation.

'Financial or Other Competing Interest': None.

Submission 19-12-2018, Peer Review 12-02-2019,

Acceptance 19-02-2019, Published 04-03-2019.

Corresponding Author:

Dr. Lissiamma George,

Additional Professor,

Department of Obstetrics and Gynaecology,

GMC, Thrissur,

Kerala, India.

E-mail: drlissiammag@gmail.com

DOI: $10.14260 /$ jemds $/ 2019 / 131$

\section{(c) (i) $(9)$}

The reasons for continued rise in caesarean rates are increased maternal age at first delivery, widespread use of electronic fetal monitoring, rise in labour induction in primigravidae, increase in prevalence of obesity, rate for VBAC has decreased, decreased frequency of operative vaginal deliveries and in fear of malpractice litigation related to fetal injury during spontaneous or operative vaginal delivery.

Caesarean delivery has higher maternal surgical risks for current and subsequent pregnancies. Maternal morbidity associated with caesarean are infection, haemorrhage, thromboembolism, anaesthetic complications, bladder and bowel injury, hysterectomy, rehospitalisation for wound infections, longer initial hospital stays, risk of uterine rupture, abnormal placental implantation in subsequent pregnancy.

CS has several inherent complications but maternal and fetal well-being, timing of the birth, the surgeon's experience, the competence of the center, the surgical technique, and the risk of anaesthesia are factors that play important roles in the emergence of complications

The caesarean section rate is increasing worldwide as there are numerous factors which contribute to decrease in vaginal birth after caesarean section and although repeat caesarean sections are associated with serious morbidity 
there are only a few studies which assess the risk of placenta praevia and accreta in repeat caesarean section. Thus, to find out the maternal outcome in those undergoing secondary CS in our population and to find out the common indications for which primary caesarean section is done.

\section{MATERIALS AND METHODS}

A prospective observational cohort study was conducted in department of Obstetrics and Gynaecology, Government Medical College, Thrissur for a period of 1 year from January 2016 - December 2016 after permission was obtained from IRB in patients between 18 - 45 years who underwent primary caesarean section and secondary caesarean section with no prior history of any abdominal surgeries other than previous caesarean were selected. Informed consent was obtained from patients who met the inclusion criteria. Sociodemographic information was collected using the proforma by personal interview and details of intraoperative, maternal complications from their case records. Quantitative variables include maternal age at delivery, gestational age at delivery, BMI, blood transfusions if required. Qualitative variables include presence of maternal disease, adhesions, placenta praevia, visceral injury, scar rupture, postpartum haemorrhage, hysterectomy, ICU admission, post op fever, urinary tract infection, wound infection, maternal death.

\section{Statistical Analysis}

Analysis of data was done using statistical software package SPSS, version 17.0. Categorical and quantitative variables was expressed as frequency and mean \pm SD respectively. Comparison of categorical variables was performed using the chi square test with a $p$ value of $<0.05$ taken as significant.

\section{RESULTS}

The study was done in 400 patients, 200 patients in each group who underwent primary and secondary caesarean section respectively.

The mean age group of patients who had primary caesarean section was $26.4 \pm 5.2$ years, and those who underwent secondary caesarean section was $28.4 \pm 4.3$ years. Among those who underwent primary caesarean section, 29 patients $(14.5 \%)$ were below 20 years of age and 8 patients (4\%) were above 35 years of age. Majority of the patients, 112 patients $(56 \%)$ who underwent primary caesarean section were referred whereas patients who had secondary caesarean section were almost equally booked (50.5\%) and referred (49.5\%).

\begin{tabular}{|c|c|c|c|c|c|c|}
\hline \multirow{2}{*}{ Parity } & \multicolumn{2}{|c|}{ Primary CS } & \multicolumn{2}{|c|}{ Secondary CS } & \multirow{2}{*}{$\chi^{2}$} & \multirow{2}{*}{ P } \\
\cline { 2 - 5 } & Number & $\%$ & Number & \% & & \\
\hline 1 & 163 & 81.5 & 0 & 0.0 & \\
\hline 2 & 28 & 14.0 & 157 & 79 & \multirow{2}{*}{$275.31^{* *}$} & 0.000 \\
\hline 3 & 6 & 3.0 & 40 & 20.0 & & \\
\hline$>3$ & 3 & 1.5 & 2 & 1.0 & & \\
\hline \multicolumn{7}{|c|}{ Table 1. Comparison of Parity Based on Group } \\
\hline \multicolumn{7}{|c|}{ * Significant at 0.05 level }
\end{tabular}

Majority of those who underwent primary caesarean section are primipara i.e. 163 patients $(81.5 \%)$, and 37 multiparous patients $(18.5 \%)$ had a primary caesarean section. Among those who had a secondary caesarean section 157 patients (79\%) had previous 1 CS, 40 patients (20\%) had previous 2 CS and 2 patients (1\%) had previous $3 \mathrm{CS}$.
Majority of the patients were term patients 123 (61.5\%) and 139 patients (69.5\%) among those who underwent primary and secondary caesarean section respectively

In both primary and secondary CS groups, the most common medical disorder is hypertension complicating pregnancy accounting for $23 \%$ and $16 \%$ respectively, followed closely by diabetes complicating pregnancy which accounts for $22 \%$ and $15 \%$ respectively.

In primary caesarean section group the other medical disorders seen are hypothyroidism (4\%), anaemia complicating pregnancy (2.5\%), cardiac disease complicating pregnancy $(1 \%)$, asthma (1\%), seizure disorder (1\%), bipolar disorder $(0.5 \%)$ in order of decreasing frequency.

In secondary caesarean section group the other medical disorders were hypothyroidism (6\%), cardiac disease $(4.5 \%)$, anaemia complicating pregnancy $(3,5 \%)$, bipolar disorder $(0.5 \%)$, Sjogren's disease $(0.5 \%)$, Varicella $(0.5 \%)$ in order of decreasing frequency.

The mean BMI is $23.47 \pm 1.95 \mathrm{~kg} / \mathrm{m}^{2}$ in the primary CS group and $24.34 \pm 1.55 \mathrm{~kg} / \mathrm{m}^{2}$ in the secondary CS group

In primary $\mathrm{CS}$ group the main indications are fetal distress (20\%), failed induction (13\%), primi breech (12\%), grade 2/3 MSAF unfavourable cervix (9\%), CPD failed trial (8.5\%), IUGR with abnormal Doppler (8.5\%), placenta praevia (7.5\%), arrest of decent (5.5\%) in decreasing order of frequency.

In secondary CS group the main indications were previous CS, unfavourable cervix (63.5\%), previous 2 CS (18.5\%) and only $3.5 \%$ had placenta praevia.

Blood transfusion was required in 25 patients $(12.5 \%)$ of primary caesarean section group and 17 patients $(8.5 \%)$ in secondary caesarean section group. There was no significant association in this study.

\begin{tabular}{|c|c|c|c|c|c|c|}
\hline \multirow{2}{*}{$\begin{array}{c}\text { Intra OP } \\
\text { Complications }\end{array}$} & \multicolumn{2}{|c|}{ Primary CS } & \multicolumn{2}{|c|}{ Secondary CS } & \multirow[b]{2}{*}{$\chi^{2}$} & \multirow[b]{2}{*}{$\mathbf{P}$} \\
\hline & Number & $\%$ & Number & $\%$ & & \\
\hline Adhesions & 3 & 1.5 & 121 & 60.5 & 162.74 & 0.000 \\
\hline Bladder Injury & 1 & 0.5 & 2 & 1.0 & 0.34 & 0.562 \\
\hline Scar Dehiscence & 1 & 0.5 & 8 & 4.0 & $5.57^{*}$ & 0.018 \\
\hline Hysterectomy & 0 & 0.0 & 2 & 1.0 & 2.01 & 0.156 \\
\hline $\mathrm{PPH}$ & 39 & 19.5 & 18 & 9.0 & $9.02^{*}$ & 0.003 \\
\hline \multicolumn{7}{|c|}{$\begin{array}{l}\text { Table 2. Comparison of Intra Operative Complications } \\
\text { Based on Group }\end{array}$} \\
\hline \multicolumn{7}{|c|}{ *: - Significant at 0.05 level } \\
\hline
\end{tabular}

In primary CS group the main intra operative complication is post-partum haemorrhage (19.5\%) and adhesions $(60.5 \%)$ and scar dehiscence $(4 \%)$ are the main intraoperative complication in secondary CS group. There is significant association of adhesion, scar dehiscence and PPH in secondary caesarean section. There was only 1 Caesarean hysterectomy with bladder injury repair in this study and was not statistically significant.

\begin{tabular}{|c|c|c|c|c|c|c|}
\hline Post OP ICU & \multicolumn{2}{|c|}{ Primary CS } & \multicolumn{2}{|c|}{ Secondary CS } & \multirow{2}{*}{ P } \\
\cline { 2 - 5 } Admission & Number & $\%$ & Number & $\%$ & & \\
\hline Yes & 87 & 43.5 & 63 & 31.5 & \multirow{2}{*}{$6.14^{*}$} & \multirow{2}{*}{0.013} \\
\hline No & 113 & 56.5 & 137 & 68.5 & & \\
\hline Table 3. Comparison of Post OP ICU Based on Group \\
\hline \multicolumn{7}{|c|}{$*$ : - Significant at 0.05 level } \\
\hline
\end{tabular}

In primary CS group 87 patients $(43.5 \%)$ and in secondary CS group 63 patients (31.5\%) required post-op ICU admission which was statistically significant. $(\mathrm{p}$ value $=$ 0.013) 
In this study there was wound infection in 10 patients $(5 \%)$ in primary caesarean section and 15 patients $(7.5 \%)$ in secondary caesarean section, 28 patients $(14 \%)$ in primary CS group and 20 patients (10\%) in secondary CS group had urinary tract infection which was not statistically significant.

\section{DISCUSSION}

Serious maternal morbidity increases with increasing number of cesarean deliveries.[1,2,3,4] The majority of this risk is attributable to that associated with placenta accreta and/or the need for hysterectomy.[5] In our study there was no significant association between placenta previa and accreta with secondary CS. In a study by Silver et al,[3] placenta accreta was present in more than $2 \%$ of patients having their fourth and in $6.7 \%$ of those undergoing their sixth or greater cesarean delivery. In the absence of placenta accreta or the need for hysterectomy, there still was an association between maternal morbidity and increasing cesarean delivery number for all morbidities.

Previous studies examining the risk of surgical morbidity with repeat cesarean delivery have reported mixed results. Some have reported no association. $[6,7]$

Makoha and colleagues[8] also noted increased maternal morbidity, including placenta previa, placenta accreta, hysterectomy, adhesions, bladder injury,[9] postoperative hemoglobin deficit, and need for blood transfusion with increasing number of cesarean deliveries.

Although repeat cesarean delivery was associated with increased maternal morbidity, outcomes were good in most women undergoing these procedures. Women should be counseled regarding the progressive increase in the risk for meaningful morbidity with repeat cesarean deliveries.[10,11]

However, Hershkowitz and colleagues found no association between many cesarean deliveries and placenta previa. [6] We cannot comment on the relative effects of parity, a known risk factor for placenta previa, because our cohort included only cesarean deliveries, as opposed to all deliveries.

A major limitation of this study was its small size.

We believe that our data have important implications for counseling patients regarding elective cesarean delivery and trial of labor after previous cesarean delivery. Although the general safety of cesarean delivery is well established, morbidity from multiple procedures may not be taken into account. It is important to consider not only the morbidity from the initial cesarean delivery, but that from subsequent pregnancies as well.[12-16] Thus, women planning large families should consider the risks of repeat cesarean deliveries when contemplating elective cesarean delivery or attempted vaginal birth after cesarean delivery. Our data also will facilitate counseling of women with placenta previa and prior cesarean deliveries regarding their risks of placenta accrete.

\section{CONCLUSION}

Majority of the CS were emergency CS in both groups. Most common indications in primary CS group were fetal distress (20\%), failed induction (13\%), primi, breech (12\%) and in secondary CS group was previous CS with unfavourable cervix (63.5\%). There was no significant association between placenta praevia and secondary CS in this study. Adhesions $(60.5 \%)$ and scar dehiscence (4\%) were most common intra op complications in secondary CS group and were statistically significant with a $p$ value of $(0.00)$ and $(0.018)$ respectively.
PPH (19.8\%) was the most common intra operative complication in primary CS group with a $\mathrm{p}=0.003$ and was statistically significant. There was only 1 Caesarean hysterectomy with bladder injury repair in secondary CS group and was not statistically significant.

Post op ICU admission was statistically significant in primary CS group.

In a developing country like India, where the population growth rate is ever increasing, women who have undergone a primary caesarean section must be counselled regarding the complications and possible maternal morbidity in subsequent pregnancies and must be motivated for trial of scar in subsequent pregnancies if there is no contraindication.

\section{REFERENCES}

[1] Saha L, Chowdhury SB. Study on primary cesarean section. Mymensingh Med J 2011;20(2):292-7.

[2] Tulandi T, Agdi M, Zarei A, et al. Adhesion development and morbidity after repeat cesarean delivery. Am J Obstet Gynecol 2009;201(1):56.e1-e6.

[3] Silver RM, Landon MB, Rouse DJ, et al. Maternal morbidity associated with multiple cesarean deliveries. Obstet Gynecol 2006;107(6):1226-32.

[4] Lyell DJ. Adhesions and perioperative complications of repeat cesarean delivery. Am J Obstet Gynecol 2011;205(Suppl 6):S11-S8.

[5] Lydon-Rochelle M, Holt VL, Easterling TR, et al. Firstbirth cesarean and placental abruption or previa at second birth(1). Obstet Gynecol 2001;97(5 Pt 1):7659.

[6] Hershkowitz R, Fraser D, Mazor M, et al. One or multiple previous cesarean sections are associated with similar increased frequency of placenta previa. Eur J Obstet Gynecol Reprod Biol 1995;62(2):185-8.

[7] Khong TY. The pathology of placenta accreta, a worldwide epidemic. J Clin Pathol 2008;61(12):12436.

[8] Makoha FW, Felimban HM, Fathuddien MA, et al. Multiple cesarean section morbidity. Int J Gynaecol Obstet 2004;87(3):227-32.

[9] Tarney CM. Bladder injury during cesarean delivery. Current Women's Health Rev 2013;9(2):70-6.

[10] Kaplanoglu M, Bulbul M, Kaplanoglu D, et al. Effect of multiple repeat cesarean sections on maternal morbidity: data from Southeast Turkey. Med Sci Monit 2015;21:1447-53.

[11] Galyean AM, Lagrew DC, Bush MC, et al. Previous cesarean section and the risk of postpartum maternal complications and adverse neonatal outcomes in future pregnancies. J Perinatol 2009;29(11):726-30.

[12] Lynch CM, Kearney R, Turner MJ. Maternal morbidity after elective repeat caesarean after two or more previous procedures. Eur J Obstset Gynecol Reprod Bio 2003;106(1):10-3.

[13] Maanongun MT, Ornguze AA, Ojabo AA, et al. Indications and the materno-foetal outcome of caesarean section in a secondary health facility in obudu, south-south Nigeria. Res Rep Gynaecol \& Obstet 2017;1(3):3-9. 
[14] Shobha T, Jyothi. Study of maternal and neonatal outcome of primary cesarean section at term influence of labour and stage. International Journal of Science and Research 2016;5(4):2213-8.

[15] Suriyaprabha K, Vibala S. A study on maternal and fetal outcome in emergency primary cesarean section. Journal of Dental and Medical Sciences 2017;16(4):239.
[16] Clark EAS, Silver RM. Long-term maternal morbidity associated with repeat cesarean delivery. Am J of Obstet \& Gynecol 2011;205(Suppl 6):S2-S10. 